\title{
Successful Chemotherapy with Nab-Paclitaxel in a Heavily Treated Non-Small Cell Lung Cancer Patient: A Case Report
}

\author{
Mikiko Ishihara $^{a}$ Satoshi Igawa ${ }^{a}$ Sachiyo Maki ${ }^{a}$ Shinya Harada ${ }^{a}$ \\ Seiichiro Kusuhara ${ }^{a}$ Hideyuki Niwa $^{a}$ Sakiko Otani ${ }^{a}$ Jiichiro Sasaki ${ }^{b}$ \\ Shi-Xu Jiang ${ }^{c}$ Noriyuki Masuda ${ }^{a}$ \\ ${ }^{a}$ Department of Respiratory Medicine, ${ }^{b}$ Research and Development Center for New \\ Medical Frontiers, and 'Department of Pathology, Kitasato University School of Medicine, \\ Sagamihara, Japan
}

\section{Key Words}

Non-small cell lung cancer · Chemotherapy $\cdot$ Nab-paclitaxel

\begin{abstract}
Non-small cell lung cancer (NSCLC) accounts for the majority of all lung cancers. A 69-yearold female with postoperatively recurrent NSCLC was treated weekly with nanoparticlealbumin-bound paclitaxel (nab-paclitaxel) monotherapy every 4 weeks as a tenth line chemotherapy, and stable disease was achieved by seven cycles of this regimen. The patient developed grade 4 neutropenia and grade 3 leukopenia, but none of the other toxicities, including febrile neutropenia and peripheral neuropathy, were severe, and thus she was able to tolerate this salvage chemotherapy. To our knowledge this is the first report of the efficacy of nab-paclitaxel monotherapy in a heavily treated NSCLC patient.

(c) 2014 S. Karger AG, Basel
\end{abstract}

\section{Introduction}

Lung cancer is a major cause of cancer deaths. Non-small cell lung cancer (NSCLC) accounts for approximately $85 \%$ of all lung cancers [1]. Platinum-based chemotherapy has been considered the standard therapy worldwide for patients with advanced NSCLC. Several phase III studies have demonstrated a promising efficacy of EGFR-TKIs as individualized treatment for advanced NSCLC patients on the basis of their EGFR gene mutation status [2-

Satoshi Igawa

Department of Respiratory Medicine, Kitasato University School of Medicine

1-15-1 Kitasato

Minami-ku, Sagamihara 252-0374, Kanagawa (Japan)

E-Mail igawa@kitasato-u.ac.jp 
4]. Unfortunately, all patients with advanced NSCLC ultimately experience disease progression. A recent study of weekly nanoparticle-albumin-bound paclitaxel (nab-paclitaxel) in combination with carboplatin in patients with previously untreated stage III/IV NSCLC yielded encouraging efficacy results [5]. Below, we report the case of a heavily treated NSCLC patient who experienced stable disease with nab-paclitaxel monotherapy.

\section{Case Report}

In April 2005, a 69-year-old female was diagnosed with lung adenocarcinoma that harbored an EGFR mutation in the form of an exon 19 deletion by transbronchial lung biopsy (fig. 1a), and a right upper lobectomy was performed (fig. 1b). The pathological stage was IA. In November 2007, regional metastasis to the subcarinal lymph nodes was diagnosed, and the patient was treated with concurrent chemo-radiotherapy consisting of cisplatin plus vinorelbine and a 60-Gy dose of thoracic radiotherapy. Metastasis to the left occipital lobe, the cervical spine, a sacral vertebra and the right femur was diagnosed, and each metastatic lesion was treated by local radiotherapy. Lung and liver metastases were then detected, and the patient was treated with the following eight chemotherapy regimens: docetaxel, gefitinib, erlotinib, pemetrexed, carboplatin plus paclitaxel plus bevacizumab, S-1, amrubicin and gemcitabine. In August 2013, disease progression due to the increase of lung and liver metastases was identified (fig. 2a). Performance status and major organ function had been maintained, and the patient could accordingly receive a tenth line chemotherapy by nabpaclitaxel at a dose of $100 \mathrm{mg} / \mathrm{m}^{2}$, which was repeated on day 1,8 and 15 every 4 weeks. The toxicity profile reported as the highest grades during the first cycle of this regimen was: hematological toxicity in the form of grade 4 neutropenia, grade 3 leukopenia and grade 1 anemia, and non-hematologic toxicity in the form of grade 1 dysgeusia, oral mucositis, constipation, and alopecia. At the start of the second cycle of this regimen, the nab-paclitaxel dose was reduced from 100 to $80 \mathrm{mg} / \mathrm{m}^{2}$ and administrated on day 1 and 8 every 4 weeks from the second to the seventh cycle. Computed tomography (CT) of the chest revealed a $21 \%$ decrease in the total diameter of lung and liver metastases by four cycles of this regimen, indicating stable disease according to the RECIST criteria (fig. 2b). The patient has maintained stable disease by seven cycles of this regimen at present in May 2014 (fig. 2c). In addition, although the serum CEA level exceeded the institutional upper limit of the normal value $(<5 \mathrm{ng} / \mathrm{ml})$, it seemed to be remarkably decreased by this regimen (fig. 3 ).

\section{Discussion}

The nab-paclitaxel formulation was developed to deliver paclitaxel as a suspension of albumin particles in saline, thereby allowing a shorter infusion time and use of a standard infusion set. This new Cremophor EL-free formulation does not require steroid and antihistamine premedication to prevent hypersensitivity reactions. Nab-paclitaxel is a 130$\mathrm{nm}$ particle form of paclitaxel, provides higher local concentrations of paclitaxel in the tumor microenvironment and has a stronger tumor-killing capability [6-8]. Two studies $[9,10]$ have reported overall response rates of 30.0 and $28.6 \%$, respectively, and median progression-free survival times of 5.0 and 4.0 months, respectively, in patients with advanced NSCLC who had previously received chemotherapy.

This article reports a case of successful nab-paclitaxel monotherapy in a heavily treated patient with advanced NSCLC. We would especially like to emphasize the fact that an 
antitumor effect was shown despite a history of treatment with nine previous chemotherapy regimens, and that a disease control was seen in the absence of any serious nab-paclitaxel toxicity even though the patient had a history of treatment with a solvent-based paclitaxel. Although there have been no reports of the efficacy of nab-paclitaxel monotherapy in patients with advanced NSCLC who had previously been treated with paclitaxel, the results of a prospective study [11] indicated that weekly treatment with $100 \mathrm{mg} / \mathrm{m}^{2}$ nab-paclitaxel was well-tolerated in patients with advanced breast cancer who had been heavily treated with taxanes, that there were no hypersensitivity reactions, there was a low rate of treatment cessation because of peripheral neuropathy, and that the objective response rate was $16 \%$ in this setting. Another study [12] reported that nab-paclitaxel had greater antitumor activity than equitoxic doses of Cremophor-based paclitaxel in the following five human tumor xenograft models: lung (H522), breast (MX-1), ovarian (SK-OV-3), prostate (PC-3), and colon (HT29). Interestingly, the same study reported that intra-tumor paclitaxel concentrations were 33\% higher following the administration of nab-paclitaxel than following the administration of equal doses of Cremophor-based paclitaxel in the MX-1 xenograft model. The higher intra-tumor concentrations after the administration of nabpaclitaxel were supported by data showing a 9.9-fold increase in endothelial cell binding of nab-paclitaxel, a 4.2 -fold increase in endothelial transcytosis of nab-paclitaxel, inhibition of endothelial cell binding of paclitaxel in the presence of Cremophor, and inhibition of albumin binding of paclitaxel in the presence of Cremophor [12].

To our knowledge, this is the first report indicating a disease control in a heavily treated advanced NSCLC patient by nab-paclitaxel monotherapy. Because of the activity of nabpaclitaxel against NSCLC, a prospective study to evaluate its efficacy and safety in patients with NSCLC refractory to conventional chemotherapy, including taxane chemotherapy, is warranted.

\section{Disclosure Statement}

None of the authors have any conflicts of interest to report.

\section{References}

1 Siegel R, DeSantis C, Virgo K, Stein K, Mariotto A, Smith T, et al: Cancer treatment and survivorship statistics, 2012. CA Cancer J Clin 2012;62:220-241.

-2 Mok TS, Wu YL, Thongprasert S, Yang CH, Chu DT, Saijo N, et al: Gefitinib or carboplatin-paclitaxel in pulmonary adenocarcinoma. N Engl J Med 2009;361:947-957.

3 Maemondo M, Inoue A, Kobayashi K, Sugawara S, Oizumi S, Isobe H, et al: Gefitinib or chemotherapy for nonsmall-cell lung cancer with mutated EGFR. N Engl J Med 2010;362:2380-2388.

-4 Mitsudomi T, Morita S, Yatabe Y, Negoro S, Okamoto I, Tsurutani J, et al: Gefitinib versus cisplatin plus docetaxel in patients with non-small-cell lung cancer harbouring mutations of the epidermal growth factor receptor (WJTOG3405): an open label, randomised phase 3 trial. Lancet Oncol 2010;11:121-128.

5 Socinski MA, Bondarenko I, Karaseva NA, Makhson AM, Vynnychenko I, Okamoto I, et al: Weekly nabpaclitaxel in combination with carboplatin versus solvent-based paclitaxel plus carboplatin as first-line therapy in patients with advanced non-small-cell lung cancer: final results of a phase III trial. J Clin Oncol 2012;30:2055-2062.

-6 Das M, Wakelee H: Anti-angiogenic agents in Non-Small-Cell Lung Cancer (NSCLC): a perspective on the MONET1 (Motesanib NSCLC Efficacy and Tolerability) study. J Thorac Dis 2012;4:558-561.

7 Rizvi NA, Riely GJ, Azzoli CG, Miller VA, Ng KK, Fiore J, et al: Phase I/II trial of weekly intravenous 130-nm albumin-bound paclitaxel as initial chemotherapy in patients with stage IV non-smallcell lung cancer. J Clin Oncol 2008;26:639-643. 


\section{Case Reports in Oncology}

\begin{tabular}{l|l}
\hline Case Rep Oncol 2014;7:401-406 & \\
\hline DOI: $10.1159 / 000364857$ & $\begin{array}{l}\text { @ 2014 S. Karger AG, Basel } \\
\text { www.karger.com/cro }\end{array}$ \\
\hline
\end{tabular}

Ishihara et al.: Successful Chemotherapy with Nab-Paclitaxel in a Heavily Treated NonSmall Cell Lung Cancer Patient: A Case Report

-8 Stinchcombe TE, Socinski MA, Lee CB, Hayes DN, Moore DT, Goldberg RM, et al: Phase I trial of nanoparticle albumin-bound paclitaxel in combination with gemcitabine in patients with thoracic malignancies. J Thorac Oncol 2008;3:521-526.

-9 Zheng Q, Yao Y, Nan K: Weekly intravenous nanoparticle albumin-bound paclitaxel for elderly patients with stage IV non-small-cell lung cancer: a series of 20 cases. J Biomed Res 2012;26:159-164.

10 Xing PY, Li JL, Wang Y, Hao XZ, Wang B, Yang L, et al: Efficacy and safety of albumin-bound paclitaxel in treating recurrent advanced non-small-cell lung cancer. Chin J Cancer Res 2013;25:200-205.

11 Blum JL, Savin MA, Edelman G, Pippen JE, Robert NJ, Geister BV, et al: Phase II study of weekly albuminbound paclitaxel for patients with metastatic breast cancer heavily pretreated with taxanes. Clin Breast Cancer 2007;7:850-856.

12 Desai N, Trieu V, Yao Z, Louie L, Ci S, Yang A, et al: Hawkins M, Soon-Shiong P. Increased antitumor activity, intratumor paclitaxel concentrations, and endothelial cell transport of cremophor-free, albumin-bound paclitaxel, ABI-007, compared with cremophor-based paclitaxel. Clin Cancer Res 2006;12:1317-1324.
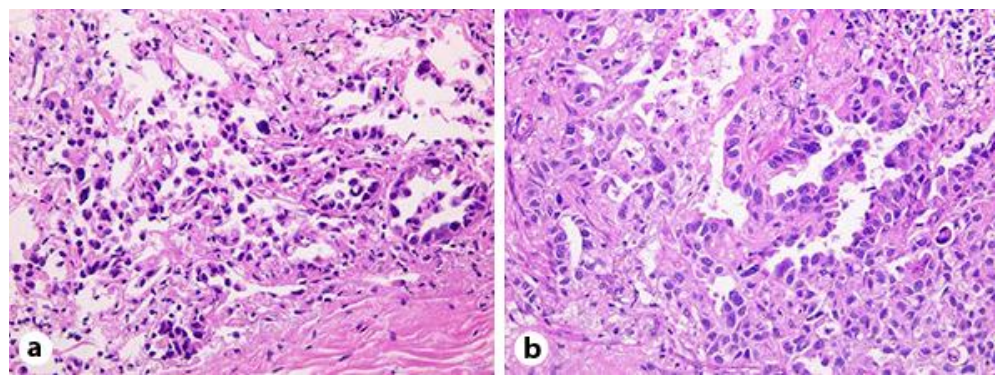

Fig. 1. a Although the biopsied material was somewhat crushed, growth of the cuboid tumor cells was observed mainly along the existing alveolar walls. Thus, the tumor was diagnosed as an adenocarcinoma. b A solid tumor with prominent indentation was revealed at the periphery in the resected upper lobe of the right lung. Microscopically, although lepidic growth was also observed at the periphery of the tumor, the majority of the tumor cells were mainly arranged in irregular papillae, and thus a final pathological diagnosis of moderately differentiated adenocarcinoma was made. 
Ishihara et al.: Successful Chemotherapy with Nab-Paclitaxel in a Heavily Treated NonSmall Cell Lung Cancer Patient: A Case Report
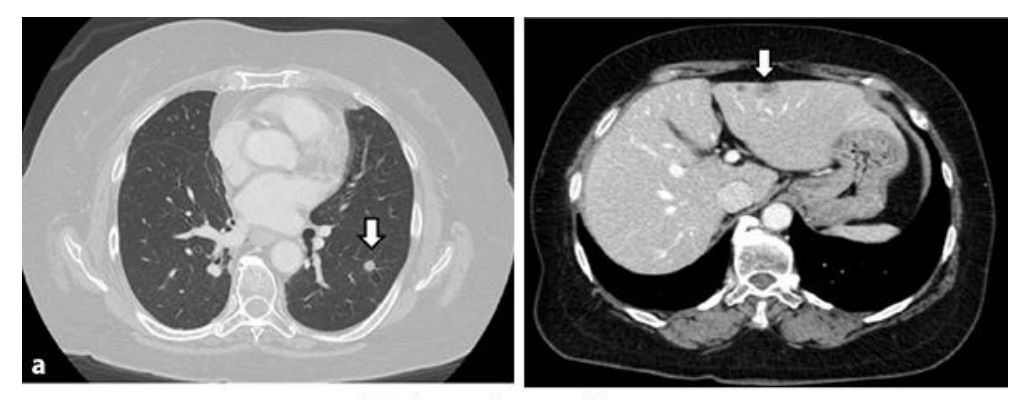

Before chemotherapy
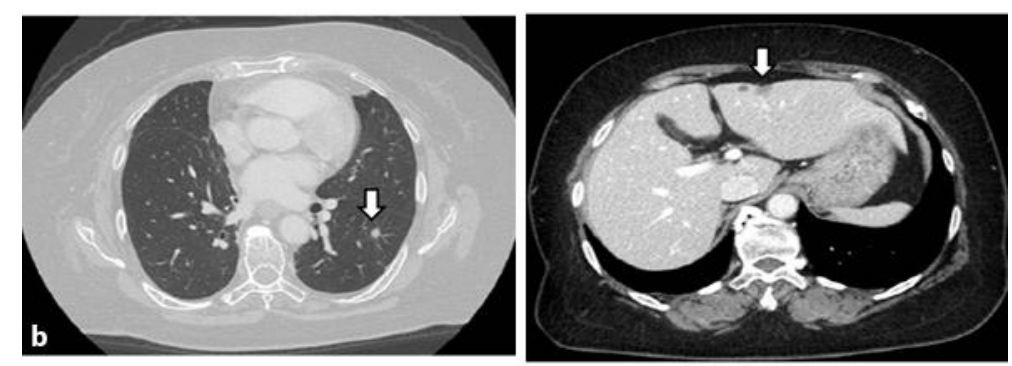

After 4 cycles of chemotherapy
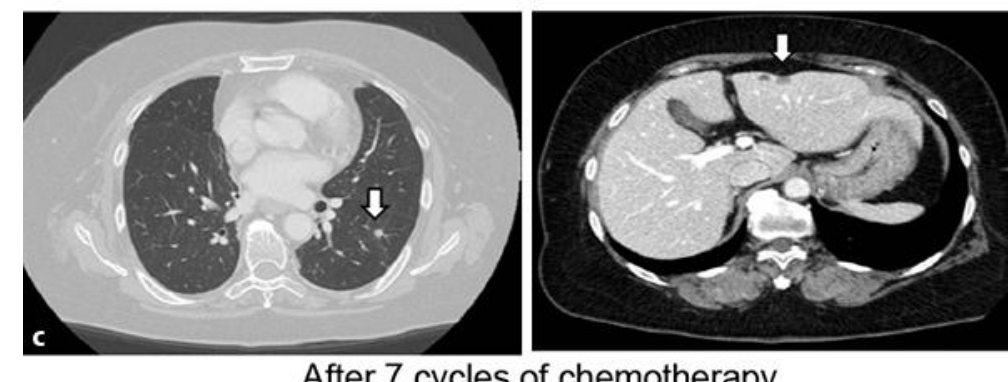

After 7 cycles of chemotherapy

Fig. 2. CT of the chest before chemotherapy (a), after 4 cycles of chemotherapy (b), and after 7 cycles of chemotherapy (c). The size of the lung and liver metastases had decreased (b), and no disease progression was observed (c). 


\begin{tabular}{l|l}
\hline DOI: $10.1159 / 000364857$ & $\begin{array}{l}\text { @ 2014 S. Karger AG, Basel } \\
\text { www.karger.com/cro }\end{array}$ \\
\hline
\end{tabular}

www.karger.com/cro

Ishihara et al.: Successful Chemotherapy with Nab-Paclitaxel in a Heavily Treated NonSmall Cell Lung Cancer Patient: A Case Report

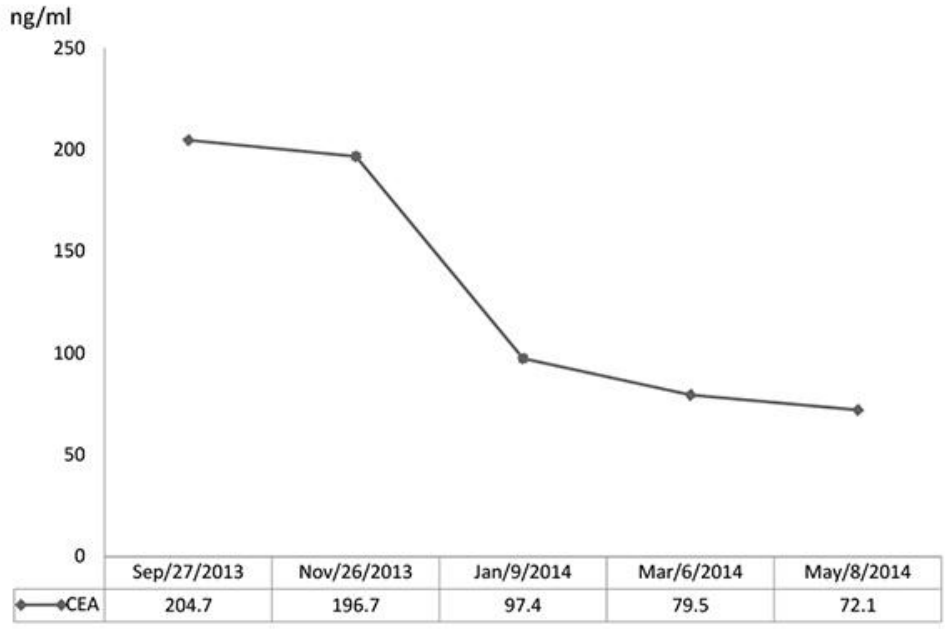

Fig. 3. Changes in the serum CEA level. 